\title{
Ingestion of a single serving of saury alters postprandial levels of plasma n-3 polyunsaturated fatty acids and long-chain monounsaturated fatty acids in healthy human adults
}

\author{
Zhi-Hong Yang ${ }^{*}$, Hiroko Miyahara, Jiro Takeo and Masashi Katayama
}

\begin{abstract}
Background: Saury oil contains considerable amounts of n-3 polyunsaturated fatty acids (PUFA) and monounsaturated fatty acids (MUFA) with long aliphatic tails ( $>18 C$ atoms). Ingestion of saury oil reduces the risk of developing metabolic syndrome concomitant with increases in n-3 PUFA and long-chain MUFA in plasma and organs of mice. We therefore evaluated changes in postprandial plasma fatty acid levels and plasma parameters in healthy human subjects after ingestion of a single meal of saury.

Findings: Five healthy human adults ingested $150 \mathrm{~g}$ of grilled saury. Blood was collected before the meal and at 2, 6, and $24 \mathrm{hr}$ after the meal, and plasma was prepared. Plasma levels of eicosapentaenoic acid, docosahexaenoic acid, and long-chain MUFA (C20:1 and C22:1 isomers combined) increased significantly throughout the postprandial period compared with the pre-meal baseline. Postprandial plasma insulin concentration increased notably, and plasma levels of glucose and free fatty acids decreased significantly and subsequently returned to the pre-meal levels.

Conclusions: Our study suggests that a single saury meal may alter the postprandial plasma levels of n-3 PUFA and long-chain MUFA in healthy human subjects.
\end{abstract}

Keywords: Saury, n-3 PUFA, MUFA, Eicosapentaenoic acid (EPA), Docosahexaenoic acid (DHA)

\section{Background}

Increasing evidence from animal and human experiments has demonstrated that two particular long-chain n-3 polyunsaturated fatty acids (PUFA), i.e., eicosapentaenoic acid (EPA) and docosahexaenoic acid (DHA), have been associated with multiple positive health effects including improvement of obesity and diabetes mellitus [1], cardiovascular and neurodegenerative diseases [2,3], asthma [4], and inflammatory diseases [5]. Furthermore, we previously reported that a fish oil-derived concentrate containing long-chain monounsaturated fatty acids (MUFA), i.e., C20:1 and C22:1 isomers combined, alleviated metabolic syndrome partly by regulating genes involved in lipid metabolism, energy expenditure, and

\footnotetext{
* Correspondence: yangzh@nissui.co.jp

Central Research Laboratory, Tokyo Innovation Center, Nippon Suisan Kaisha, Ltd., 32-3 Nanakuni 1 Chome Hachioji, Tokyo 192-0991, Japan
}

inflammation in obese mice [6]. In addition to $n-3$ PUFA, saury oil and pollock oil contain considerable amounts of long-chain MUFA $[7,8]$. Ingestion of saury oil or pollock oil countered the risk of developing metabolic syndrome and increases the plasma levels of $n-3$ PUFA and long-chain MUFA as well as the $n-3 / n-6$ PUFA ratio in obese mice, suggesting a correlation between plasma levels of n-3 PUFA and long-chain MUFA and metabolic parameters $[9,10]$. However, limited information is available on the effect of saury meal ingestion on the plasma n-3 PUFA and long-chain MUFA accumulation in normal human subjects.

In this study, we investigated changes in plasma levels of EPA, DHA, and long-chain MUFA after ingestion of a single meal of saury. To our knowledge, this is the first report evaluating the effect of a single ingestion of saury on postprandial fatty acid composition and in plasma of healthy human subjects. 


\section{Methods}

Five healthy Asian adult volunteers (four Japanese and one Chinese; four males and one female; age range 3040 years) in the experiment had normal serological measures, and they did not take any medications known to affect carbohydrate or lipoprotein metabolism or insulin secretion or its activity. All the participants lived in Japan, and regularly consumed traditional rice-based diets. Basal data of subjects are shown in Table 1. The study was approved by the ethics committee of Nippon Suisan Kaisha (Tokyo, Japan). Commercially prepared grilled saury (Maruko Foods, Shizuoka, Japan) was used in the study. After total lipid in the saury $(150 \mathrm{~g})$ was extracted by the Folch method [11], the fatty acid composition (Table 2) was determined as the methyl esters of fatty acids by gas-liquid chromatography. Measurement of the composition of the grilled saury was performed by Japan Food Research Laboratories (Tokyo, Japan), and the composition is shown in Table 3.

The study was conducted after the subjects adhered to a 12-hr overnight fast, and fasting blood samples were collected at approximately 09:00 in the morning. Then, each subject ingested $150 \mathrm{~g}$ of grilled saury along with one rice ball within $15 \mathrm{~min}$. Lunch was a medium-size plain noodle eaten between 12:00 and 12:30 at noon. Supper (medium-size rice or noodles) was ingested before 21:00 (19:00 20:00), and the subjects' diet was restricted such that foods enriched in n-3 PUFA and/or MUFA were not consumed. No other meals or snacks between the three meals were ingested until the end of the experiment. Blood samples were collected at $2 \mathrm{hr}$ and $6 \mathrm{hr}$ after ingestion of the saury meal. Then, a final blood sample was collected at $24 \mathrm{hr}$ after ingestion, and this was preceded by another 12-hr fast. Plasma was obtained by centrifuging each blood sample at $3000 \mathrm{rpm}$ for $10 \mathrm{~min}$ at $4^{\circ} \mathrm{C}$, and stored at $-80^{\circ} \mathrm{C}$ until analysis. For

Table 1 Basal data of subjects before the experiment

\begin{tabular}{lr}
\hline Age (years) & $35.1 \pm 2.5$ \\
\hline Height $(\mathrm{cm})$ & $169.2 \pm 1.7$ \\
\hline Body weight $(\mathrm{kg})$ & $60.8 \pm 1.1$ \\
\hline BMl $\left(\mathrm{kg} / \mathrm{m}^{2}\right)$ & $21.2 \pm 0.7$ \\
\hline Plasma glucose $(\mathrm{mg} / \mathrm{dL})$ & $96.8 \pm 3.8$ \\
\hline Plasma insulin $(\mu / \mathrm{U} / \mathrm{L})$ & $1.9 \pm 0.4$ \\
\hline Plasma lipids profile & \\
\hline TC $(\mathrm{mg} / \mathrm{dL})$ & $191.2 \pm 5.8$ \\
\hline $\mathrm{HDL}-\mathrm{C}(\mathrm{mg} / \mathrm{dL})$ & $67.1 \pm 6.8$ \\
\hline LDL-C (mg/dL) & $99.4 \pm 10.2$ \\
\hline TG $(\mathrm{mg} / \mathrm{dL})$ & $99.6 \pm 14.3$ \\
\hline FFA $(\mathrm{mEq} / \mathrm{L})$ & $0.30 \pm 0.05$ \\
\hline
\end{tabular}

BMI: Body mass index, TC: total cholesterol, HDL-C: high-density lipoprotein cholesterol, LDL-C: low-density lipoprotein cholesterol, TG: triglyceride, FFA: free fatty acid.
Table 2 Major fatty acid composition of saury used in the study

\begin{tabular}{lr}
\hline FA (\%) & \\
\hline C14:0 & 10.22 \\
\hline C16:0 & 10.37 \\
\hline C18:0 & 1.80 \\
\hline C20:0 & 0.17 \\
\hline Total saturated FA & 18.56 \\
\hline C16:1 n-7 & 1.94 \\
\hline C18:1 n-9 & 4.07 \\
\hline C20:1 n-9 & 12.55 \\
\hline C20:1 n-7 & 4.15 \\
\hline C22:1 n-11 & 20.08 \\
\hline C22:1 n-9 & 1.22 \\
\hline Total MUFA & 44.01 \\
\hline C18:2n-6 & 1.32 \\
\hline C18:3n-6 & 0.16 \\
\hline C20:2n-6 & 0.26 \\
\hline C20:4n-6 & 0.42 \\
\hline Total n-6 PUFA & 2.16 \\
\hline C18:3n-3 & 1.27 \\
\hline C20:3n-3 & 0.18 \\
\hline C20:5n-3 & 5.24 \\
\hline C22:5n-3 & 1.09 \\
\hline C22:6n-3 & 12.07 \\
\hline Total n-3 PUFA & 19.85 \\
\hline n-3/n-6 PUFA ratio & 9.19 \\
\hline FA:Fatty acds MUFA: & \\
\hline
\end{tabular}

FA: Fatty acids, MUFA: monounsaturated fatty acids, PUFA: polyunsaturated fatty acids.

each time point of the study, lipids were extracted from plasma using methanol/hexane, and the fatty acid composition was determined as described [9]. Postprandial plasma total cholesterol, high-density lipoprotein (HDL)cholesterol, low-density lipoprotein (LDL)-cholesterol, triglycerides, free fatty acids, and glucose were determined enzymatically using commercially available reagent kits (Wako Pure Chemical Industries, Ltd., Osaka, Japan), and plasma insulin concentration was measured with an enzyme-linked immunosorbent assay kit (Morinaga Institute of Biological Science, Inc., Yokohama, Japan). The data are presented as mean $\pm \mathrm{SE}$, and the data between the fasting (time zero) and postprandial time points were compared. All statistical tests were performed using the Student's t-test, and statistical significance was considered as $P<0.05$.

\section{Results and discussion}

The level of n-3 PUFA (EPA, DHA, and total n-3 PUFA) in plasma peaked at $6 \mathrm{hr}$ after saury ingestion and then gradually declined (Figure 1a). At $24 \mathrm{hr}$ post-ingestion, plasma EPA rose by $196 \%(P<0.001)$, DHA rose by $25 \%$ 
Table 3 Composition of saury used in the study

\begin{tabular}{lr}
\hline Component $\mathbf{( g / 1 0 0 ~ g ) ~}$ & \\
\hline Moisture & 48.9 \\
\hline Protein & 25.9 \\
\hline Lipids & 21.7 \\
\hline Ash & 4.2 \\
\hline Carbohydrates & 0.1 \\
\hline Energy (kcal/100 g) & 299
\end{tabular}

$(P<0.05)$, and total n-3 PUFA rose by $65 \%(P<0.01)$ compared with the pre-ingestion values. In contrast, plasma total n-6 PUFA levels remained essentially unchanged throughout the postprandial period (Figure 1b). Thus, the measured increase in n-3 PUFA level coupled with the lack of change in n-6 PUFA resulted in the notable increase $(P<0.05)$ in n-3/n-6 PUFA ratio from $2 \mathrm{hr}$ to $24 \mathrm{hr}$ after the saury meal (Figure 1c). Concerning plasma MUFA levels, long-chain MUFA C20:1 (n-9 and $\mathrm{n}-7$ ) and C22:1 (n-11 and n-9) peaked at 2 hr post-
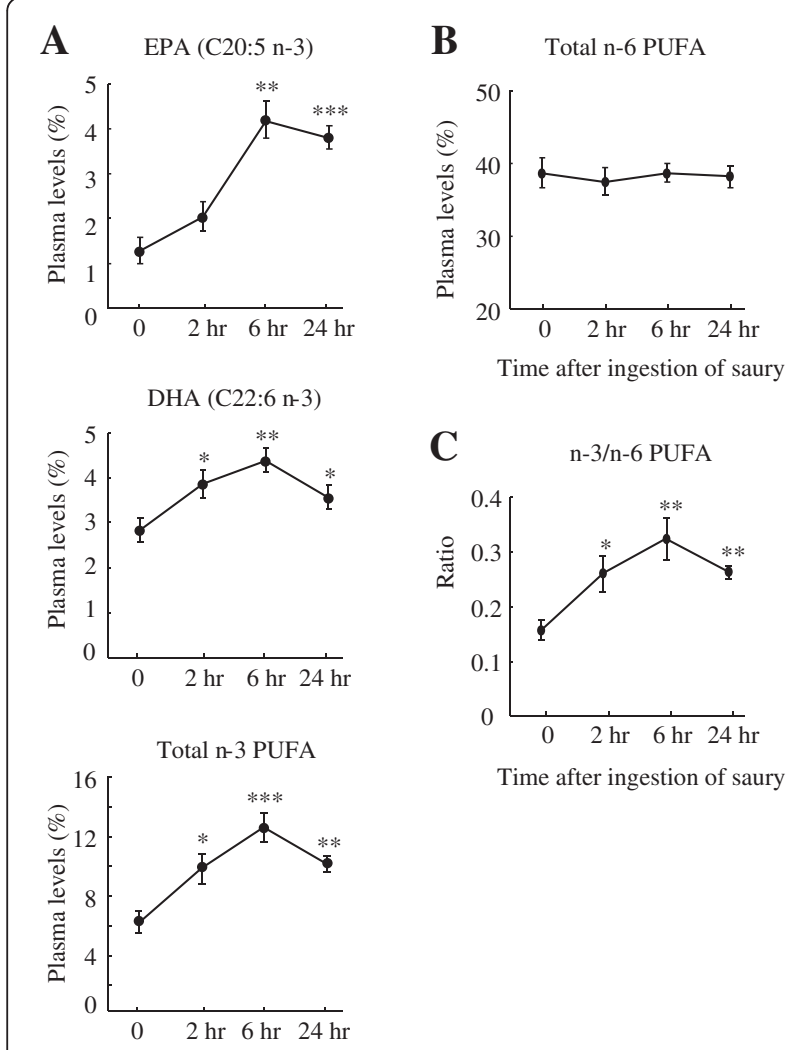

Time after ingestion of saury

\footnotetext{
Time after ingestion of saury
}

Figure 1 Changes in levels of plasma PUFA. Plasma levels (\% of total plasma fatty acids) of EPA, DHA, and total n-3 PUFA (A), total n-6 PUFA (B), and n-3/n-6 PUFA ratio (C) are shown. The data were collected before and after the ingestion of a single saury meal. Values represent the mean $\pm \mathrm{SE}, \mathrm{n}=5$. ${ }^{*} P<0.05$; ${ }^{* *} P<0.01$; ${ }^{* * *} P<0.001$ as compared to pre-ingestion values (time 0 ).

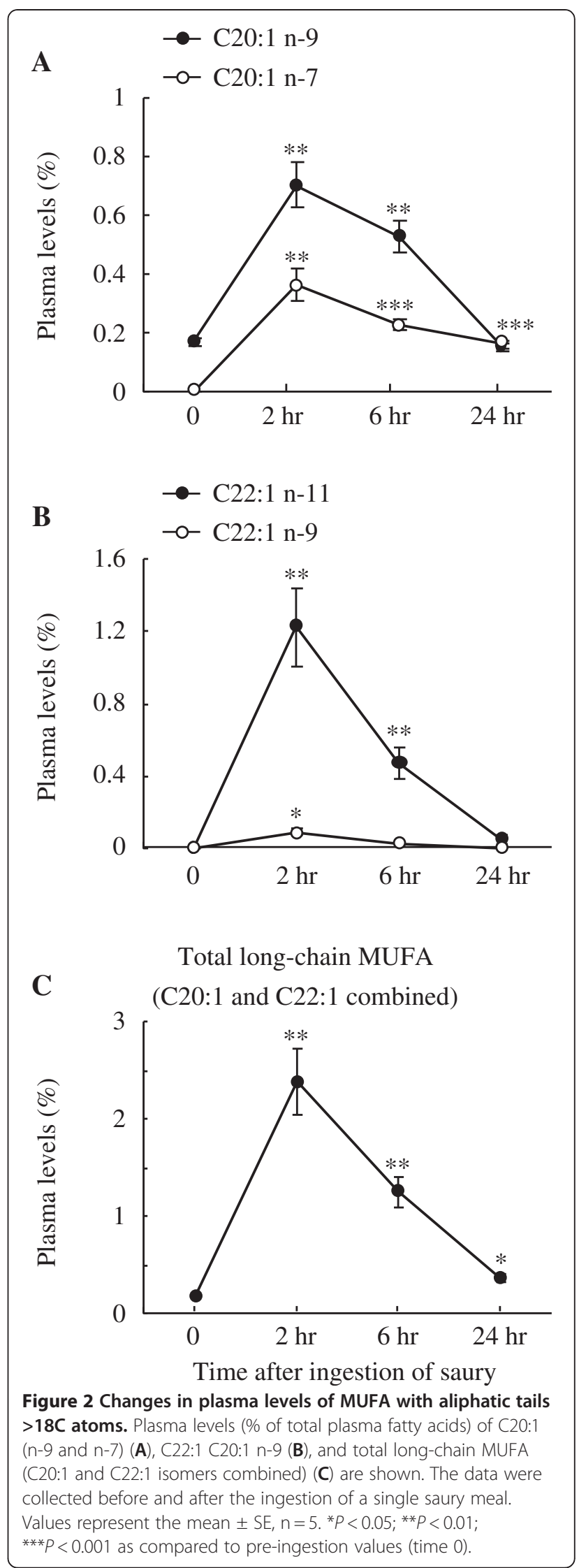




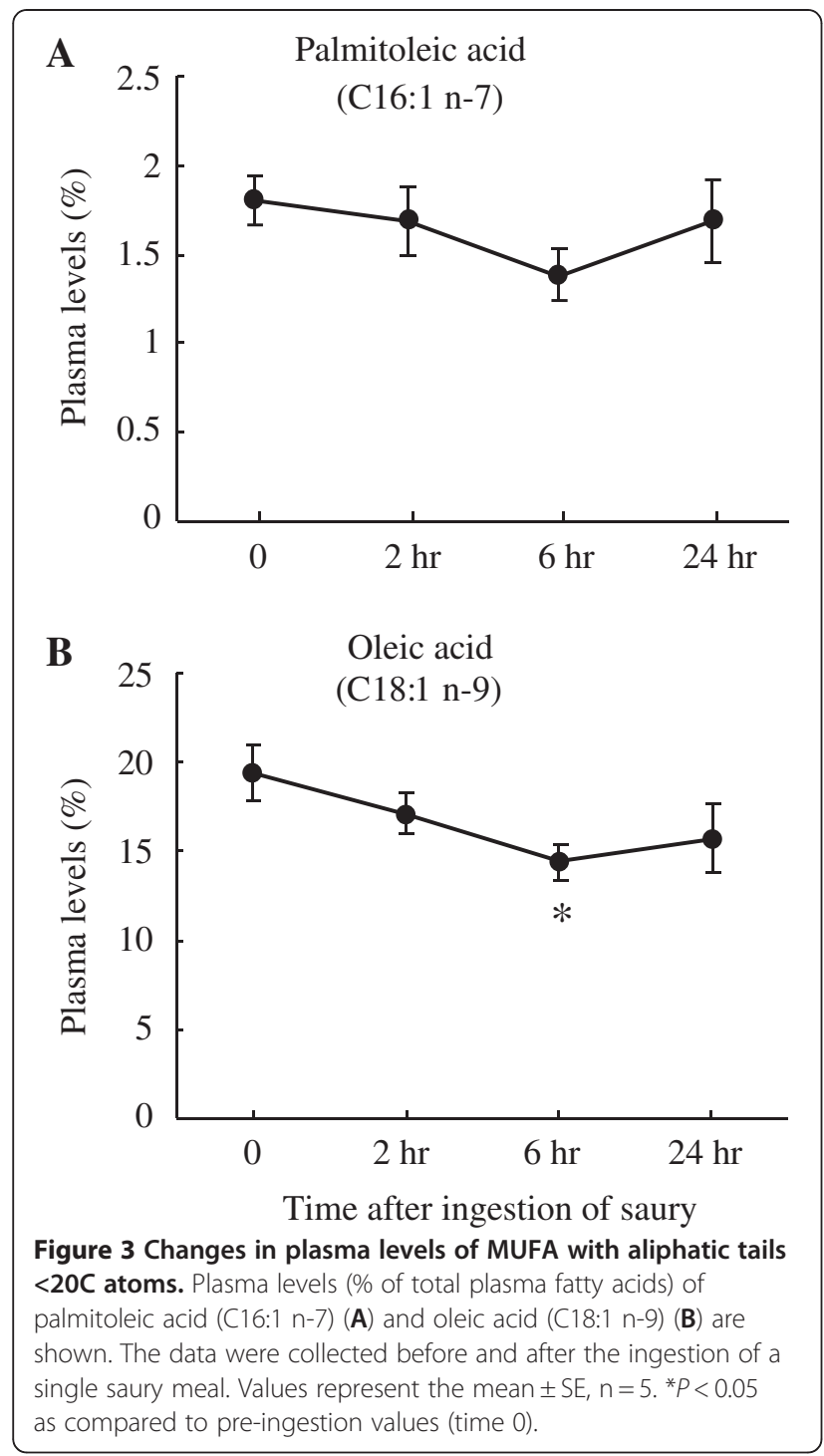

ingestion (Figure 2a and b). Accordingly, plasma total long-chain MUFA (C20:1 and C22:1 isomers combined) increased from the fasting level of $0.17 \pm 0.02 \%$ to $2.38 \pm 0.34 \%$ at $2 \mathrm{hr}$ after the saury meal and then declined sharply, although the value was still 1.2-fold higher $(P<0.05)$ than the basal value by the end of the study (Figure 2c). On the other hand, as shown in Figure 3, plasma levels of the shorter-chain MUFA (aliphatic tails $<20 \mathrm{C}$ atoms) palmitoleic acid (C16:1 n-7) and oleic acid (C18:1 n-9) tended to decline throughout the experiment; the oleic acid level decreased by $26 \%(P<0.05)$ at $6 \mathrm{hr}$ after the saury meal. The long-chain MUFA gondoic acid $(\mathrm{C} 20: 1 \mathrm{n}-9)$ and erucic acid (C22:1 n-9) are biosynthesized from oleic acid, and C20:1 n-7 is derived from palmitoleic acid by a series of chain-elongation reactions towards the carboxyl terminus [12]. Thus, the observed decrease in postprandial plasma levels of shorter-chain
MUFA was possibly related to the elevated levels of circulating long-chain MUFA. Studies on the relationship between plasma fatty acid composition in Greenland Eskimos and the composition of Eskimo food have indicated that plasma levels of EPA/DHA as well as longchain MUFA were found to reflect dietary intakes of these fatty acids $[13,14]$. The saury meal $(150 \mathrm{~g})$ used in the current study contained approximately $6 \mathrm{~g}$ of EPA and DHA combined and $12 \mathrm{~g}$ of C20:1 and C22:1 combined, which provided an abundant source of long-chain n-3 PUFA and long-chain MUFA. Furthermore, Osterud et al. [15] reported that the consumption of whale oil rich in n-3 PUFA (EPA and DHA) as well as long-chain MUFA (C20:1 and C22:1 isomers) by healthy subjects for

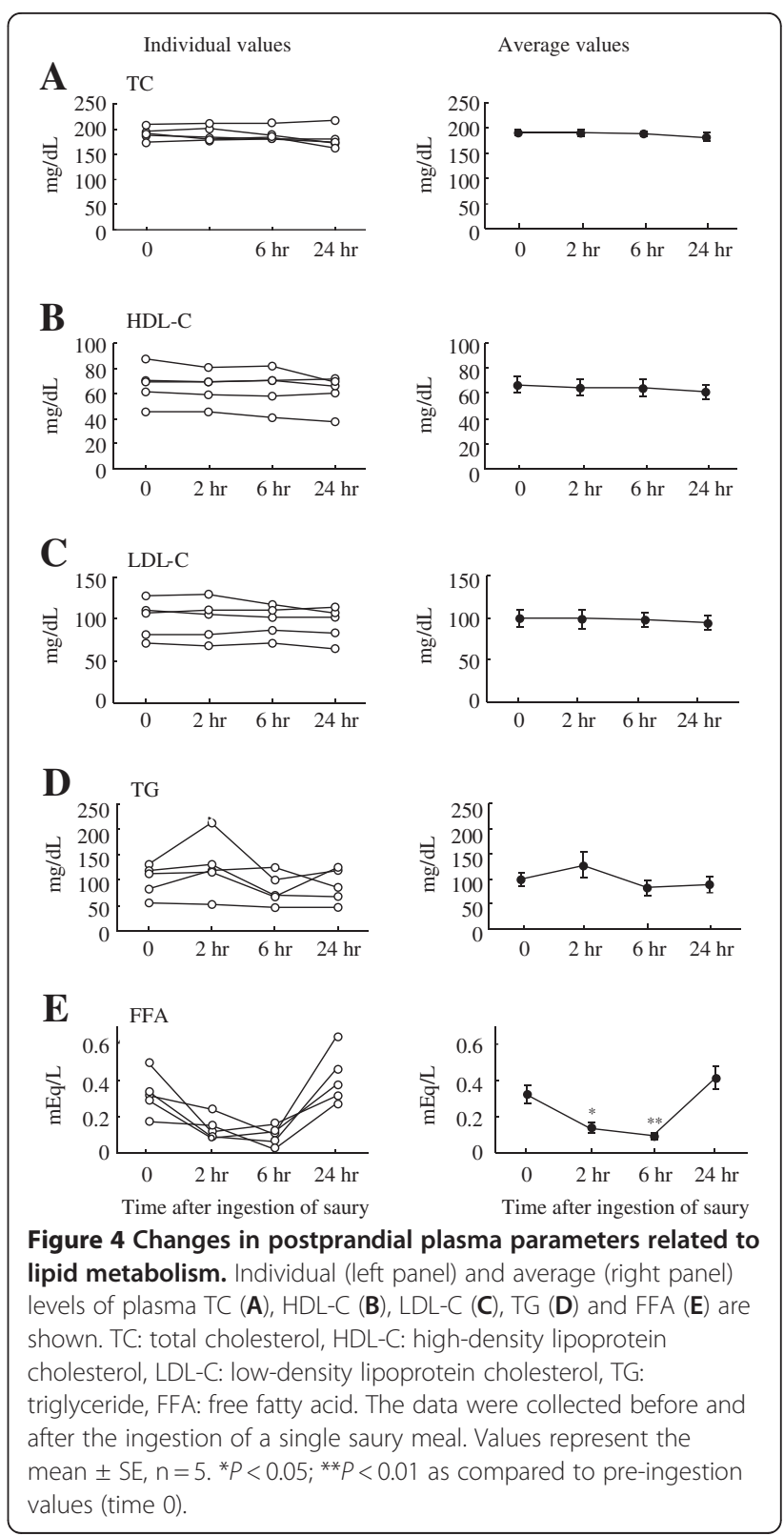




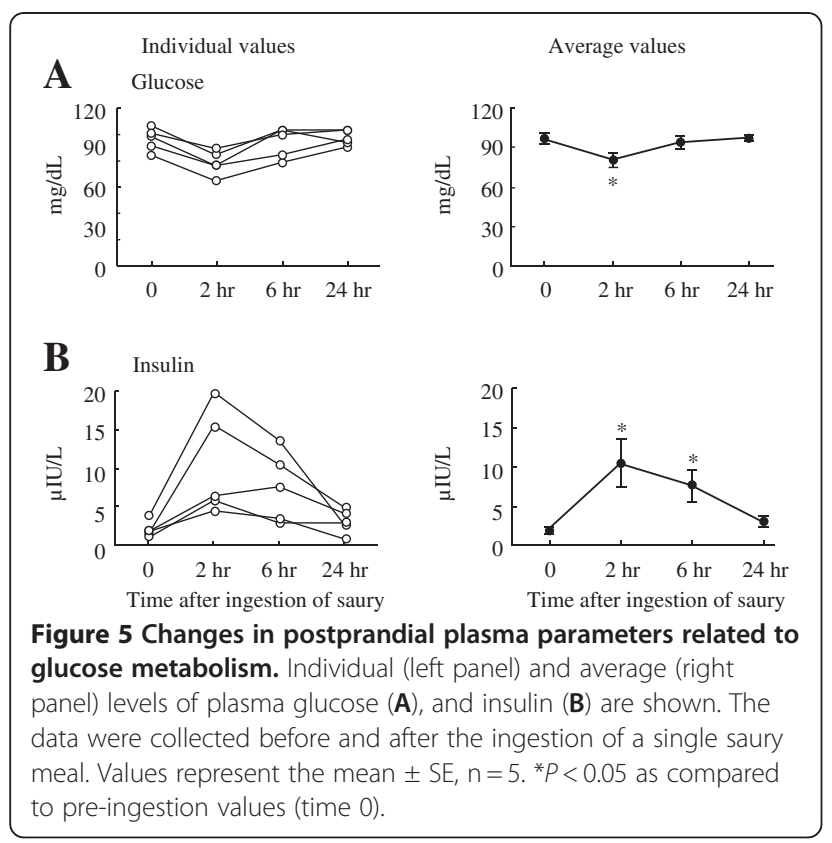

10 weeks significantly increased the serum levels of these fatty acids. It is therefore suggested that the sharp increases in plasma levels of long-chain n-3 PUFA and long-chain MUFA during the postprandial term in the current study were possibly due to the saury meal, which may possibly lead to the accumulation of these fatty acids in plasma after long-term ingestion of fish oil enriched in long-chain n-3 PUFA and long-chain MUFA. In a further study, we will investigate fatty acid alterations in response to dietary saury intake in a larger number of human subjects.

Plasma concentrations of free fatty acids decreased from a baseline value of $0.32 \pm 0.05 \mathrm{mEq} / \mathrm{mL}$ to $0.14 \pm 0.03 \mathrm{mEq} / \mathrm{mL}(P<0.05)$ at $2 \mathrm{hr}$ and $0.09 \pm 0.02$ $\mathrm{mEq} / \mathrm{mL}(P<0.01)$ at $6 \mathrm{hr}$ after the saury meal and then returned to the basal level by $24 \mathrm{hr}$ (Figure 4e), although there were no differences in plasma levels of total cholesterol (Figure 4a), HDL-cholesterol (Figure 4b), LDLcholesterol (Figure 4c) and triglyceride (Figure 4d) throughout the experimental period. Plasma glucose $(97 \pm 4 \mathrm{mg} / \mathrm{dL}$, basal $)$ decreased by $17 \%(P<0.05)$ at $2 \mathrm{hr}$ post-ingestion and then returned to basal levels (Figure 5a). In contrast, plasma insulin concentration increased from $1.9 \pm 0.4 \mu \mathrm{IU} / \mathrm{L}$ to $10.5 \pm 3.1 \mu \mathrm{IU} / \mathrm{L}$ $(P<0.05)$ by $2 \mathrm{hr}$ and to $7.6 \pm 2.0 \mu \mathrm{IU} / \mathrm{L}(P<0.05)$ by $6 \mathrm{hr}$ in response to the saury meal and returned to the basal level by the end of the study (Figure 5b). It has been well documented that insulin plays a crucial physiological role in postprandial glucose homeostasis and in inhibiting adipose tissue lipolysis, which may lead to reduced release of fatty acids into the blood stream $[16,17]$. Thus, the hyperinsulinemia after the saury meal may have caused the observed acute decreases in plasma glucose and free fatty acids. It has been reported that dietary fats of varying degree of unsaturation exert different effects on postprandial glucose/lipid homeostasis, and a MUFArich diet improves insulin sensitivity acutely [18]. Nevertheless, we could not exclude the possibility that other components in the meal were involved in the observed changes in the postprandial plasma parameters. To clarify the effectiveness of saury on mitigating the postprandial insulin response, it is necessary to directly compare the saury oil and other dietary fats.

\section{Abbreviations}

DHA: docosahexaenoic acid; EPA: eicosapentaenoic acid;

MUFA: monounsaturated fatty acids; PUFA: polyunsaturated fatty acids.

\section{Competing interests}

The authors declare that they have no competing interests.

\section{Authors' contributions}

Conceived and designed the experiments: ZHY, HM, JT and MK. Performed the experiments: $\mathrm{ZHY}$ and HM. Analyzed the data and wrote the paper: $\mathrm{ZHY}$.

Received: 18 March 2012 Accepted: 24 July 2012

Published: 30 July 2012

\section{References}

1. Delarue J, LeFoll C, Corporeau C, Lucas D: $\mathbf{n}-3$ long chain polyunsaturated fatty acids: a nutritional tool to prevent insulin resistance associated to type 2 diabetes and obesity?. Reprod Nutr Dev 2004, 44:289-299.

2. Wang C, Harris WS, Chung M, Lichtenstein AH, Balk EM, Kupelnick B, Jordan HS, Lau J: n-3 Fatty acids from fish or fish-oil supplements, but not alpha-linolenic acid, benefit cardiovascular disease outcomes in primary- and secondary-prevention studies: a systematic review. Am J Clin Nutr 2006, 84:5-17.

3. Yurko-Mauro K: Cognitive and cardiovascular benefits of docosahexaenoic acid in aging and cognitive decline. Curr Alzhemier Res 2010, 7:190-196.

4. Fasano E, Serini S, Piccioni E, Innocenti I, Calviello G: Chemoprevention of lung pathologies by dietary n-3 polyunsaturated fatty acids. Curr Med Chem 2010, 17:3358-3376.

5. Calder PC: $n-3$ polyunsaturated fatty acids, inflammation, and inflammatory diseases. Am J Clin Nutr 2006, 83:1505S-1519S.

6. Yang ZH, Miyahara H, Mori T, Doisaki N, Hatanaka A: Beneficial effects of dietary fish-oil-derived monounsaturated fatty acids on metabolic syndrome risk factors and insulin resistance in mice. J Agric Food Chem 2011, 59:7482-7489.

7. Ota T, Takagi T, Kosaka S: Changes in lipids of young and adult saury cololabis saira (Pisces). Mar Ecol Prog Ser 1980, 3:11-17.

8. Oliveira ACM, Bechtel PJ: Lipid composition of Alaska pink salmon (Oncorhynchus gorbuscha) and Alaska walleye pollock (Theragra chalcogramma). J Aquat Food Prod Tech 2005, 14:73-91.

9. Yang ZH, Miyahara $H$, Takemura S, Hatanaka A: Dietary saury oil reduces hyperglycemia and hyperlipidemia in diabetic KKAy mice and in diet-induced obese $\mathrm{C57BL} / 6 \mathrm{~J}$ mice by altering gene expression. Lipids 2011, 46:425-434.

10. Yang ZH, Miyahara H, Takeo J, Hatanaka A, Katayama M: Pollock oil supplementation modulates hyperlipidemia and ameliorates hepatic steatosis in mice fed a high-fat diet. Lipids Health Dis 2011, 10:189.

11. Folch J, Lees M, Stanley GHS: A simple method for the isolation and purification of total lipids from animal tissues. J Biol Chem 1956, 226:497-509.

12. Jakobsson A, Westerberg R, Jacobsson A: Fatty acid elongases in mammals: Their regulation and roles in metabolism. Prog Lipid Res 2006, 45:237-249.

13. Bang HO, Dyerberg J, Sinclair HM: The composition of the Eskimo food in north western Greenland. Am J Clin Nutr 1980, 33:2657-2661. 
14. Dyerberg J, Bang HO, Hjorne N: Fatty acid composition of the plasma lipids in Greenland Eskimos. Am J Clin Nutr 1975, 28:958-966.

15. Osterud B, Elvevoll E, Barstad H, Brox J, Halvorsen H, Lia K, Olsen JO, Olsen RO, Sissener C, Rekdal O, Vogild E: Effect of marine oils supplementation on coagulation and cellular activation in whole blood. Lipids 1995, 30:1111-1118.

16. Lafontan M, Langin D: Lipolysis and lipid mobilization in human adipose tissue. Prog Lipid Res 2009, 48:275-297.

17. Campbell PJ, Carlson MG, Hill JO, Nurjhan N: Regulation of free fatty acid metabolism by insulin in humans: role of lipolysis and reesterification. Am J Physiol 1992, 263:E1063-F1069.

18. López S, Bermúdez B, Pacheco YM, Villar J, Abia R, Muriana FJ: Distinctive postprandial modulation of beta cell function and insulin sensitivity by dietary fats: monounsaturated compared with saturated fatty acids. Am J Clin Nutr 2008, 88:638-644.

doi:10.1186/1476-511X-11-95

Cite this article as: Yang et al:: Ingestion of a single serving of saury alters postprandial levels of plasma $\mathrm{n}-3$ polyunsaturated fatty acids and long-chain monounsaturated fatty acids in healthy human adults. Lipids in Health and Disease 2012 11:95.

\section{Submit your next manuscript to BioMed Central and take full advantage of:}

- Convenient online submission

- Thorough peer review

- No space constraints or color figure charges

- Immediate publication on acceptance

- Inclusion in PubMed, CAS, Scopus and Google Scholar

- Research which is freely available for redistribution 